\title{
ON SUPERCONTINUOUS FUNCTIONS IN TOPOLOGY
}

\author{
Ramesh Bhat ${ }^{*}$ 四 \\ ${ }^{* 1}$ Assistant Professor, Gokhale Centenary College, Ankola, Karnataka, India
}

DOI: https://doi.org/10.29121/ijetmr.v8.i4.2021.903

Article Citation: Ramesh Bhat. (2021). ON SUPERCONTINUOUS FUNCTIONS IN TOPOLOGY. International Journal of Engineering Technologies and Management Research, 8(4), 1-5. https://doi.org/10.29121/ijetmr.v8 .i4.2021.903

Published Date: 12 April 2021

Keywords:

Super Continuous Functions T3 Spaces

Neighbourhood Functions ECT

\begin{abstract}
The aim of this paper is to introduce and study new classes of continuous functions and its properties in topological spaces comparing with different types of continuous functions.
\end{abstract}

\section{INTRODUCTION}

In this paper we studed the basic concepts of super-continuous and their basic results and some other useful results have been studied. Super-continuous maps were first introduced and investigated by B. M. Munshi and D. S. Bassan [1] in 1982. Later J. L. Reilly and M. K. Vamanamoorthi [2] continued the study of super-continuous mappings and obtained many useful results in 1983.

Super continuous functions contained in the class of continuous functions. Munshi and Bassan [1] defined the super-continuous map as follows: A map $\mathrm{f}: \mathrm{X} \rightarrow \mathrm{Y}$ is said to be super-continuous at a point $\mathrm{x} \in \mathrm{X}$ if for every neighbourhood M of $\mathrm{f}(\mathrm{x})$ there is a neighbourhood $\mathrm{N}$ of $\mathrm{x}$ such that $\mathrm{f}(\bar{N})^{0} \subseteq \mathrm{M}$. This class is contained in the class of continuous mappings. Super-continuous mappings turn out to be the natural tool for studying nearly compact space of Singal and Mathur [5], almost regular spaces of Singal and Arya [3] and almost completely regular spaces of Singal and Arya [4], M. K. Signal and A.R. Singal [6] Almost continuous mapping and N. V. Velicko [7], H-closed topological spaces Various properties of such mappings have been discussed.

\section{PRILIMINARIES}

Throughout this dissertation work $(X, \tau),(Y, \mu)$ and $(Z, \eta)$ represent non-empty topological spaces on which no separation axioms are assumed unless explicitly stated, and they are simply written $\mathrm{X}, \mathrm{Y}$ and $\mathrm{Z}$ respectively. For a subset $A$ of $(X, \tau)$, the closure of $A$, the interior of $A$ with respect to $\tau$ are denoted by $\bar{A}$ and $A^{0}$ respectively. The complement of $A$ is denoted by $A^{c}$. Now, we recall some of the following definitions

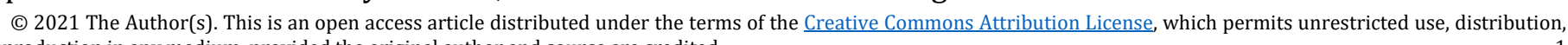
and reproduction in any medium, provided the original author and source are credited. 


\section{SUPER CONTINUOUS FUNCTIONS}

Definition 2.1 : A map $\mathrm{f}: \mathrm{X} \rightarrow \mathrm{Y}$ is said to be super-continuous at a point $\mathrm{x} \in \mathrm{X}$ if for every neighbourhood $\mathrm{M}$ of $\mathrm{f}$ (x) there is a neighbourhood $\mathrm{N}$ of $\mathrm{x}$ such that $\mathrm{f}(\bar{N})^{0} \subseteq \mathrm{M}$.

Example 2.2 : Let $X=\{a, b, c, d\}, Y=\{1,2,3,4\}, \mathfrak{I}_{1}=\{X, \phi,\{a, b\},\{a, b, d\}\}$ and $\mathfrak{I}_{2}=\{Y, \phi,\{1,3\},\{1,2,3\}\}$. Then $(X$, $\left.\mathfrak{I}_{1}\right)$ and $\left(\mathrm{Y}, \mathfrak{I}_{2}\right)$ are topological spaces.

Let $\mathrm{f}: \mathrm{X} \rightarrow \mathrm{Y}$ be a map defined as $\mathrm{f}(\mathrm{a})=\mathrm{f}(\mathrm{b})=1, \mathrm{f}(\mathrm{c})=2, \mathrm{f}(\mathrm{d})=3$.

$f$ is continuous:

1) $\mathrm{f}$ is continuous at $\mathrm{a} \in \mathrm{X}$, then for an open set $\{1,3\}$ containing $f(a)=1$, there exists an open set $\{a$, b $\}$ containing a such that $\mathrm{f}[\{\mathrm{a}, \mathrm{b}\}]=\{1\} \subseteq\{1,3\}$.

2) $f$ is continuous at $b \in X$, then for an open set $\{1,3\}$ containing $f(b)=1$, there exists an open set $\{a, b\}$ containing b such that $f[\{a, b\}]=\{1\} \subseteq\{1,3\}$.

3) $f$ is continuous at $c \in X$, then for an open set $\{1,2,3\}$ in $Y$ containing $f(c)=2$, there exists an open set $X$ containing c such that $f[X]=\{1,2,3\} \subseteq\{1,2,3\}$.

4) $f$ is continuous at $d \in X$, then for an open set $\{1,2,3\}$ in $Y$ containing $f(d)=3$, there exists an open set $X$ containing c such that $f[X]=\{1,2,3\} \subseteq\{1,2,3\}$.

Therefore, $\mathrm{f}$ is continuous as each point of $\mathrm{X}$.

\section{$f$ is not super - continuous at $x=a$ :}

For an open set $\{1,3\}$ in $Y$ containing $\mathrm{f}(\mathrm{a})=1$, there is a neighbourhood $\quad\{\mathrm{a}, \mathrm{b}\}$ of a such that $\mathrm{f}[\overline{\{a, b\}}]^{\mathrm{o}}=\mathrm{f}(\mathrm{X}$ J $=X \not \subset\{1,3\}$.

Therefore, $\mathrm{f}$ is not super continuous at $\mathrm{x}=\mathrm{a}$.

Definition 2.3 : A mapping $\mathrm{f}: \mathrm{X} \rightarrow \mathrm{Y}$ is said to be super-continuous [denoted by SC] if it is super-continuous at each point of $X$.

Definition 2.4 : A set $G$ is said to be $\delta$-open if for each $x \in G$, there exists a regular open set $H$ such that $x \in H \subseteq G$, or equivalently $\mathrm{G}$ can be expressed as arbitrary union of regular open sets.

A set $\mathrm{G}$ is $\delta$-closed if and only if its complement is $\delta$-open.

Theorem.2.5: Let $\mathrm{f}: \mathrm{X} \rightarrow \mathrm{Y}$ be a map. Then the following are equivalent.

1) $f$ if super continuous.

2) Inverse image of every open subset of $Y$ is a $\delta$-open subset of $X$.

3 ) Inverse image of every closed subset of $Y$ is a $\delta$-closed subset of $X$.

4) For each point $x$ of $X$ and for each open neighbourhood $M$ of $f(x)$, there is a $\delta$-open neighbourhood $N$ of $x$ such that $\mathrm{f}(\mathrm{N}) \subset \mathrm{M}$.

Proof: $(\mathrm{a}) \Rightarrow$ (b): Suppose (a) holds.

Let $U$ be any open subset of $Y$ and let $x \in f^{-1}(U)$. Then $f(x) \in U$. Since $f$ is super continuous, from (a), there exists an open set $\mathrm{V}$ in $\mathrm{X}$ such that $\mathrm{x} \in \mathrm{V}$ and $\mathrm{f}\left(\overline{V^{0}}\right) \subset \mathrm{U}$. Thus $\mathrm{x} \in \overline{V^{0}} \subset \mathrm{f}^{-1}(\mathrm{U})$. Therefore $\mathrm{f}^{-1}(\mathrm{U})$ is expressible as an arbitrary union of regularly open sets. Hence $\mathrm{f}^{-1}(\mathrm{U})$ is $\delta$-open.

(b) $\Rightarrow$ (c): Let $U$ be a closed set in $Y$. Then $Y-U$ is open set of $Y$. Then from (b), $f^{-1}(Y-U)$ is $\delta$-open subset of $X$. Therefore $\mathrm{f}^{-1}(\mathrm{Y}-\mathrm{U})=\mathrm{X}-\mathrm{f}^{-1}(\mathrm{U})$ is $\delta$-open subset of $\mathrm{X}$. Hence $\mathrm{f}^{-1}(\mathrm{U})$ is $\delta$-closed set of $\mathrm{X}$.

(c) $\Rightarrow(d)$ : Let $M$ be an open set in $Y$ containing $f(x)$, that is, $f(x) \in M$. Since $Y-M$ is closed, by $(c), f^{-1}(Y-M)$ is $\delta$-closed subset of $X$. Therefore $\mathrm{f}^{-1}(\mathrm{M})$ is $\delta$-open. Also $\mathrm{x} \in \mathrm{f}^{-1}(\mathrm{M})$. Let $\mathrm{N}^{-1} \mathrm{f}^{-1}(\mathrm{M})$. Then $\mathrm{N}$ is a $\delta$-open neighbourhood of $x$ such that $f(N) \subseteq M$.

(d) $\Rightarrow$ (a): Let for each $\mathrm{x} \in \mathrm{X}$ and for each neighbourhood $\mathrm{M}$ of $\mathrm{f}(\mathrm{x})$ there is a neighbourhood $\mathrm{N}$ of $\mathrm{f}(\mathrm{x})$, so $\mathrm{N}$ is $\delta$ open neighbourhood $N$ of $x$ such that $f(N) \subseteq M$, from $(d)$. Then $f\left(\overline{N^{0}}\right) \subseteq M$. So $f$ is super continuous.

Hence the proof. 
Definition 2.6 : A space $X$ is said to be semi-regular if for each point $\mathrm{x}$ of the space and each open set $\mathrm{U}$ containing $\mathrm{x}$ there is a open set $\mathrm{V}$ such that $\mathrm{x} \in \mathrm{V} \subset \overline{V^{0}} \subset \mathrm{U}$.

Theorem 2.7: Let $\mathrm{f}: \mathrm{X} \rightarrow \mathrm{Y}$ be a continuous mapping of a semi-regular space $\mathrm{X}$ into $\mathrm{Y}$. Then $\mathrm{f}$ is super continuous.

Proof: Let $\mathrm{x} \in \mathrm{X}$ and let $\mathrm{G}$ be an open set containing $\mathrm{f}(\mathrm{x})$. Since $\mathrm{f}$ is continuous, $\mathrm{f}^{-1}(\mathrm{G})$ is open in $\mathrm{X}$. Since $\mathrm{X}$ is semiregular space, there is an open subset $\mathrm{M}$ of $\mathrm{x}$ such that $\mathrm{x} \in \mathrm{M} \subset \overline{\mathrm{M}^{0}} \subseteq \mathrm{f}^{-1}(\mathrm{G})$. Therefore $\mathrm{f}(\mathrm{x}) \in \mathrm{f}(\mathrm{M}) \subseteq \mathrm{f}\left(\overline{\mathrm{M}^{0}}\right) \subseteq \mathrm{G}$. That is, $\mathrm{f}\left(\overline{M^{0}}\right) \subseteq \mathrm{G}$. Hence $\mathrm{f}$ is super continuous.

Remark 2.8 : Every open set in a $\mathrm{T}_{3}$-space can be written as the union of regular open sets.

Corollary 2.9 : Let $X$ be a $T_{3}$ topological space and let $f: X \rightarrow Y$ be a continuous, then $f$ is super-continuous.

Proof: Proof follows from every regular space ( or $\left.\mathrm{T}_{3}\right)$ space is semi regular.

Theorem 2.10: Let $\mathrm{X}$ and $\mathrm{Y}$ are topological spaces. Then a mapping $\mathrm{f}: \mathrm{X} \rightarrow \mathrm{Y}$ is super-continuous if and only if the inverse image under $f$ of every member of a base ( sub base) for $Y$ is $\delta$-open in $X$.

Proof: Let $\mathrm{f}$ be super continuous and $\mathrm{B}$ be a subbase for $Y$. Since each member of $\mathrm{B}^{*}$ is open in $\mathrm{Y}$, it follows that from the Theorem that $\mathrm{f}^{-1}(\mathrm{Y})$ is $\delta$-open for every $\mathrm{Y} \in \mathrm{B}$.

Conversely, let $\mathrm{f}^{-1}(\mathrm{Y})$ be a $\delta$-open in $\mathrm{X}$ for every $\mathrm{Y} \in \mathrm{B}$ and let $\mathrm{H}$ be any open set in $\mathrm{Y}$. Let $\beta$ be a family of all finite intersections of members of $B *$ so $B$ is a base for $Y$. If $B \in \beta$, then there exists $v_{1}, v_{2} \ldots \ldots \ldots v_{n}(n$ is finite $)$ in $B *$ such that $\mathrm{B}=\mathrm{v}_{1} \cap v_{2} \cap \ldots \ldots \ldots \ldots v_{\mathrm{n}}$. Then $\mathrm{f}^{-1}(\mathrm{~B})=\mathrm{f}^{-1}\left(v_{1}\right) \cap \mathrm{f}^{-1}\left(v_{2}\right) \cap \ldots \ldots \ldots \ldots \mathrm{f}^{-1}\left(v_{\mathrm{n}}\right)$. By hypothesis, each $\mathrm{f}^{-1}\left(v_{\mathrm{i}}\right)$ is $\delta$-open in $X$ and therefore $f^{-1}(B)$ is also $\delta$-open in $X$, since $\beta$ is a base for $X . H=\cup\{B: B \in C \subset \beta\}$. Then $f^{-1}(H)=f^{-1}[\cup\{B: B \in C \subset$ $\beta\}]=\cup\left\{\mathrm{f}^{-1}(\mathrm{~B}): \mathrm{B} \in \mathrm{C}\right\}$ which is $\delta$-open in $X$, since $\mathrm{f}^{-1}(\mathrm{~B})$ is $\delta$-open in $\mathrm{X}$. Thus $\mathrm{f}^{-1}(\mathrm{H})$ is $\delta$-open in $\mathrm{X}$ for every open set $\mathrm{H}$ in $\mathrm{Y}$ and therefore $\mathrm{f}$ is super continuous.

Definition 2.11 : A point is said to be a $\delta$-adherent point of a set $P$ in a space $X$ if equivalently, every regular open set containing $\mathrm{x}$ has non-empty intersection with P.the interior of every closed neighbourhood of the point $\mathrm{x}$ intersects $\mathrm{P}$ or

Definition 2.12 : The set $(\mathrm{P})_{\delta}$ of all $\delta$-adherent point of a set $\mathrm{P}$ is called the $\delta$-closure of the set $\mathrm{P}$.

Theorem 2.13 : A mapping f from a space $X$ into another space $Y$ is super -continuous if and only if another space $Y$ is super -continuous if and only if $\mathrm{f}(\mathrm{A})_{\delta} \subset \overline{\mathrm{f}(\mathrm{A})}$ for every subset $\mathrm{A}$ of $\mathrm{X}$.

Proof: Let $\mathrm{f}$ be a super continuous. Since $\overline{\mathrm{f}(\mathrm{A})}$ is closed in $\mathrm{Y}$, then by $\mathrm{f}^{-1}(\overline{\mathrm{f}(A)})$ is $\delta$-closed in $\mathrm{X}$, since $\mathrm{f}$ is super -continuous. Now $\mathrm{f}(\mathrm{A}) \subset \overline{\mathrm{f}(A)}$ implies, $\mathrm{A} \subset \mathrm{f}^{-1}(\overline{\mathrm{f}(A)})$. Therefore $(\mathrm{A})_{\delta} \subset\left[\mathrm{f}^{-1}(\overline{\mathrm{f}(A)})\right]_{\delta} \quad \mathrm{f}^{-1}(\overline{\mathrm{f}(A)})$. Therefore $\mathrm{f}(\mathrm{A})_{\delta} \subset \mathrm{f}[\mathrm{f}-1(\overline{\mathrm{f}(A)})] \subset \overline{\mathrm{f}(A)}$. So $\mathrm{f}(\mathrm{A})_{\delta} \subset \overline{\mathrm{f}(A)}$.

Conversely, let $\mathrm{f}(\mathrm{A})_{\delta} \subset \overline{\mathrm{f}(A)}$ for every subset $\mathrm{A}$ of $\mathrm{X}$. Let $\mathrm{F}$ be any closed set in $\mathrm{Y}$ so that $\bar{F}=\mathrm{F}$. Now $\mathrm{f}^{-1}(\bar{F})$ is a subset of X implies that $\mathrm{f}\left[\mathrm{f}^{-1}(\mathrm{~F})\right]_{\delta} \subset \overrightarrow{\left.\mathrm{f}^{-1} \mathrm{f}^{-1}(F)\right]} \subset \bar{F}=\mathrm{F}$ implies $\left[\mathrm{f}^{-1}(\mathrm{~F})\right]_{\delta} \subset \mathrm{f}^{-1}(\mathrm{~F})$. Therefore $\left[\mathrm{f}^{-1}(\mathrm{~F})\right]_{\delta}=\mathrm{f}^{-1}(\mathrm{~F})$, so $\mathrm{f}$ ${ }^{-1}(\mathrm{~F})$ is $\delta$-closed set in $\mathrm{X}$. Hence $\mathrm{f}$ is super -continuous.

Theorem 2.14: A mapping $f$ from a space $X$ into another space $Y$ is super-continuous if and only if $\left[\mathrm{f}^{-1}(\mathrm{~B})\right]_{\delta} \subset \mathrm{f}$ ${ }^{-1}(\bar{B})$ for every $\mathrm{B} \subset \mathrm{Y}$.

Proof: Let $\mathrm{f}$ be super-continuous. Since $\bar{B}$ is closed in Y and since $\mathrm{f}$ is super-continuous, $\mathrm{f}-1(\bar{B})$ is $\delta$-closed set in X. Therefore $\mathrm{f}^{-1}(\bar{B})=\left[\mathrm{f}^{-1}(\bar{B})\right]_{\delta}$. Now $\mathrm{B} \subset \bar{B} \subset[(\bar{B})]_{\delta}$ implies $\left[\mathrm{f}^{-1}(\mathrm{~B})\right]_{\delta} \subset\left[\mathrm{f}^{-1}(\bar{B})\right]_{\delta}$ implies $\left[\mathrm{f}^{-1}(\mathrm{~B})\right]_{\delta} \subset \mathrm{f}^{-1}(\bar{B}$ ).

Conversely, let the condition hold and let $F$ be any closed set in $Y$. Therefore $\bar{F}=F$. Now $\left[f^{-1}(F)\right]_{\delta} \subset f^{-1}(F)=f^{-1}(F)$. But $\mathrm{f}^{-1}(\mathrm{~F}) \subset \overleftrightarrow{\mathrm{f}^{-1}(F)} \subset\left[\mathrm{f}^{-1}(\mathrm{~F})\right]_{\delta}$. Hence $\mathrm{f}^{-1}(\mathrm{~F})=\left[\mathrm{f}^{-1}(\mathrm{~F})\right]_{\delta}$. Therefore $\mathrm{f}^{-1}(\mathrm{~F})$ is $\delta$-closed set in $\mathrm{X}$. Hence $\mathrm{f}$ is supercontinuous.

Definition 2.15: A point $x$ is called a $\delta$-adherent point of a filter base $\mathrm{F}$ if and only if $\mathrm{x} \in \cap\left\{[\mathrm{F}]_{\delta}: \mathrm{F} \in \mathrm{F}\right\}$.

Definition 2.16: A filter base is said to be $\delta$-coverage of a point $\mathrm{x}$ (written as $\mathrm{F}^{\delta} \rightarrow \mathrm{x}$ ) if every regular open set containing $\mathrm{x}$ contains $\mathrm{F} \in \mathrm{T}$.

Theorem 2.17 : Let $\mathrm{f}: \mathrm{X} \rightarrow \mathrm{Y}$ be a mapping. Then $\mathrm{f}$ is super-continuous at $\mathrm{x} \in \mathrm{X}$ if and only if the filter base $\mathrm{f}(\mathrm{U}$ $(\mathrm{x})) \rightarrow \mathrm{f}(\mathrm{x})$, where $\mathrm{U}$ 
Theorem 2.18: A mapping $f: X \rightarrow Y$ is super continuous on $X$ if and only if $f(U) \rightarrow f(x)$ for each $x \in X$ and each filter base $U$ that $\delta$-converges to $\mathrm{x}$.

Proof: Assume that $\mathrm{f}$ is super continuous on $\mathrm{X}$ and let $\mathrm{U} \stackrel{\delta}{\longrightarrow} \mathrm{x}$. Let $\mathrm{W}$ be a neighbourhood of $\mathrm{f}(\mathrm{x})$. Then $\mathrm{x} \in$ $\mathrm{f}^{-1}(\mathrm{~W})$ and $\mathrm{f}^{-1}(\mathrm{~W})$ is $\delta$-open since $\mathrm{f}$ is super- continuous. Therefore $\mathrm{x} \in \mathrm{H}$ such that $\mathrm{f}(\mathrm{H}) \subset \mathrm{W}$ where $\mathrm{H}$ is regular open and $H \subset f^{-1}(W)$. Therefore, there exits $a \mathrm{u} \in \mathrm{U}$ such that $\mathrm{u} \in \mathrm{H}$. Therefore $\mathrm{f}(\mathrm{u}) \subset \mathrm{f}(\mathrm{H}) \subset \mathrm{W}$. Therefore $\mathrm{f}(\mathrm{U}) \rightarrow \mathrm{f}(\mathrm{x})$.

Conversely, let $\mathrm{W}$ be any open subset of $\mathrm{Y}$ containing $\mathrm{f}(\mathrm{x})$. Let $\mathrm{B}$ be any subset of $\mathrm{X}$. We have to prove that $\mathrm{f}([$ $\left.\mathrm{B}]_{\delta}\right) \subset \overline{f(B)}$.

Let $\mathrm{b} \in[\mathrm{B}]_{\delta}$. Let $\mathrm{U}$ be a filter base on $\mathrm{B}$ with $\mathrm{U}$ - $\delta$-covering to $\mathrm{b}$ so that $\mathrm{f}(\mathrm{U}) \rightarrow \mathrm{f}(\mathrm{b})$. Since $\mathrm{f}(\mathrm{U})$ is a filter base on $\mathrm{f}(\mathrm{B})$, therefore $\mathrm{f}(\mathrm{b}) \in[\mathrm{f}(\mathrm{B})] \subset \overline{\mathrm{f}(B)}$ Therefore $\mathrm{f}$ is super continuous.

Theorem 2.19 (Restricting the range ) : If $f: X \rightarrow Y$ is super-continuous and $f(X)$ is taken with the subspace topology then $f: X \rightarrow f(X)$ is super-continuous.

Proof : Let $f: X \rightarrow Y$ be super-continuous. Let $U$ be an open subset of $Y$ then $\quad f^{-1}(U)$ is $\delta$-open in $X$. Now $f^{\text {- }}$ $\left.{ }^{1}(U \cap f(X))=f^{-1}(U) \cap f^{-1}[f(X))\right]=f^{-1}(U) \cap X=f^{-1}(U)$ is $\delta$-open. Therefore $f: X \rightarrow Y$ is super-continuous.

Theorem 2.20 ( Expanding the range ) : Let $\mathrm{f}: \mathrm{X} \rightarrow \mathrm{Y}$ is super-continuous. If $\mathrm{Z}$ is a space having $\mathrm{Y}$ as a subspace then the function $\mathrm{h}: \mathrm{X} \rightarrow \mathrm{Z}$ obtained by expanding the range of $\mathrm{f}$ is super-continuous.

Proof: We have to show that $\mathrm{h}: \mathrm{X} \rightarrow \mathrm{Z}$ is super-continuous. As $\mathrm{Z}$ has $\mathrm{Y}$ as a subspace, $\mathrm{h}$ is the composite of the map $\mathrm{f}: \mathrm{X} \rightarrow \mathrm{Y}$ which is super-continuous and the inclusion map $\mathrm{g}: \mathrm{Y} \rightarrow \mathrm{Z}$ which is continuous. Thus, $\mathrm{h}$ is supercontinuous.

Definition 2.21 : A mapping $\mathrm{f}: \mathrm{X} \rightarrow \mathrm{Y}$ is said to be almost open if the image of every regularly open subset of $\mathrm{X}$ is an open subset of $Y$. subset of Y.

A mapping $\mathrm{f}: \mathrm{X} \rightarrow \mathrm{Y}$ is said to be almost closed if the image of every regularly closed subset of $\mathrm{X}$ is a closed

Definition 2.22: A mapping $\mathrm{f}: \mathrm{X} \rightarrow \mathrm{Y}$ is said to be almost continuous at a point $\mathrm{X} \in \mathrm{X}$ if for every neighbourhood $\mathrm{M}$ of $\mathrm{f}(\mathrm{x})$ there is a neighbourhood $\mathrm{N}$ of $\mathrm{x}$ such that $\mathrm{f}(\mathrm{N}) \subset \overline{M^{0}}$.

Theorem 2.23 : If $\mathrm{f}$ is an almost open, super-continuous mapping $\mathrm{X}$ onto $\mathrm{Y}$ and if $\mathrm{g}$ is a mapping of $\mathrm{Y}$ into $\mathrm{Z}$ then gof is super-continuous if and only if $\mathrm{g}$ is continuous.

Proof : Let $g$ be continuous. Let $G$ be an open set in $Z$. Then $g^{-1}(G)$ is open in Y. Also $f$ is super-continuous, $f$ ${ }^{1}\left(g^{-1}(G)\right)$ is $\delta$-open in X. Therefore $f^{-1}\left(g^{-1}(G)\right)=\left(g^{\circ} f\right)^{-1}(G)$ is $\delta$-open in X. Hence gof is super-continuous.

Conversely, let gof be super-continuous. Let $G$ be an open subset of $Z$. Therefore (gof)-1 $(G)$ is $\delta$-open subset of $\mathrm{X}$ since gof is super-continuous. That is $\mathrm{f}^{-1}\left(\mathrm{~g}^{-1}(\mathrm{G})\right)$ is a $\delta$-open subset in $\mathrm{X}$. Also, $\mathrm{f}$ is almost open and onto, $\mathrm{f}\left[\mathrm{f}^{-1}\right.$ $\left.\left(\mathrm{g}^{-1}(\mathrm{G})\right)\right]=\mathrm{g}^{-1}(\mathrm{G})$ is open in $\mathrm{Y}$. Hence $\mathrm{g}$ is continuous.

Theorem 2.24 : Let $\mathrm{X}, \mathrm{Y}, \mathrm{Z}$ be topological spaces and the mapping $\mathrm{f}: \mathrm{X} \rightarrow \mathrm{Y}$ be almost continuous and $\mathrm{g}: \mathrm{Y} \rightarrow$ $\mathrm{Z}$ be super-continuous. Then the composition gof $: \mathrm{X} \rightarrow \mathrm{Z}$ is continuous.

But if $\mathrm{f}: \mathrm{X} \rightarrow \mathrm{Y}$ is almost continuous and $\mathrm{g}^{\circ} \mathrm{f}: \mathrm{X} \rightarrow \mathrm{Z}$ is continuous, then $\mathrm{g}: \mathrm{Y} \rightarrow \mathrm{Z}$ need not be supercontinuous.

Example 2.25 : Let $\left(R, \mathfrak{I}_{1}\right)$ be the topological space where $\mathfrak{I}_{1}$ is the topology consisting of $\phi$, R and complements of countable subsets of $R$. Let $X=\{a, b\}$ and $\mathfrak{I}_{2}=\{X, \phi,\{a\}\}$. Let $f: R \rightarrow X$ be defined as follows:

$$
f(x)\left\{\begin{array}{l}
a \text { if } x \text { is irrational } \\
\mathrm{b} \text { if } \mathrm{x} \text { is rational }
\end{array}\right.
$$

Let $\mathrm{Y}=\{1,2\}$ and $\mathfrak{I}_{3}=\{\mathrm{Y}, \phi,\{2\}\}$. Let $\mathrm{g}: \mathrm{X} \rightarrow \mathrm{Y}$ be defined as $\mathrm{g}(\mathrm{a})=2, \quad \mathrm{~g}(\mathrm{~b})=1$. Then $\mathrm{f}: \mathrm{R} \rightarrow \mathrm{X}$ is almost continuous and gof $: \mathrm{R} \rightarrow \mathrm{Y}$ is continuous but $\mathrm{g}: \mathrm{X} \rightarrow \mathrm{Y}$ is not super-continuous. 


\section{SOURCES OF FUNDING}

This research received no specific grant from any funding agency in the public, commercial, or not-for-profit sectors.

\section{CONFLICT OF INTEREST}

The author have declared that no competing interests exist.

\section{ACKNOWLEDGMENT}

None.

\section{REFERENCES}

[1] B. M. Munshi and D. S. Bassan, Super continuous mappings, Indian. J. Pure appl. Math., 13 (1982), 229-236.

[2] M. Mrsevic, I.L. Reilly and M. K. Vamanamoorthi, J. Austral. Math Soc. 38(1985),40-54.

[3] M. K. Singal and S. P. Arya, On almost regular spaces. Math. Vesni 6 (12), (1969)1.

[4] M. K. Singal and S. P. Arya, Almost normal and almost completely regular spaces. Glasnik Mat., 25, (1970), 141152.

[5] M. K. Singal and Asha Mathur, On nearly compact spaces. Boll Un. Mat. Ital. (4),6(1969), 702-710.

[6] M. K. Singal and A.R. Singal, Almost continuous mapping. Yokohama Math. L, 16(1968), 63-73.

[7] N. V. Velicko, H-closed topological spaces, Mat. Sab. (Russian) (N.S), 70(112)(1966),98-112. 